\section{Reseña de A la sombra de los caudillos. El presidencia- lismo en el cine mexicano}

\author{
Vicente Addiego Fernández \\ vaddiego@iteso.mx
}

Instituto Tecnológico y de Estudios Superiores de Occidente, México.

https://doi.org/10.32870/ elojoquepiensa.v0i2 1.357
A la sombra de los caudillos. El presidencialismo en el cine mexicano, coordinado por Álvaro A. Fernández y Ángel Román Gutiérrez, se compone de un cúmulo de discusiones que ponen a dialogar el cine con lo político. Encuentro significativa la forma en que sus páginas van dibujando el entramado que coloca las claves para entender al cine (dispositivo y entretenimiento) y al cine mexicano (maquinaria simbólica configurante del imaginario popular de lo mexicano) como nodos no solo del régimen presidencial, sino también de una política de la mirada definida desde el poder, en donde las formas de ver constituyen una estética y una narrativa que acompañaría a la filmografia mexicana durante la primera mitad del siglo XX hasta la segunda década del siglo XXI.

El libro logra descifrar los mecanismos utilizados por el Estado para la fabricación de una imaginación política emanada desde la silla presidencial, es decir, sus autores logran desmontar, en los primeros capítulos, el aparato estatal destinado a la producción de significados y a la generación de sentido desde donde se buscaban colocar los cimientos para edificar una nueva nación y una identidad nacional sujetada al ideal revolucionario. Conforme el lector avanza, se hacen presentes otras propuestas narrativas de ficción y no ficción que entran en resistencia con el aparato ideológico gubernamental y dotan de un espíritu emancipatorio al cine mexicano.

Atender el contenido como una cronología de acontecimientos alcanza para pensar nuestra cinematografía como un entramado articulado de condiciones socio-históricas, y no como la consecuencia de una política de Estado con fecha de caducidad. Con esto quiero decir que, si bien la figura del presidente soberano y su temporalidad han determinado la administración y control del cine mexicano, existe una política de la mirada construida desde el porfiriato que ha ido sumando géneros, relatos, temáticas, personajes y puntos de vista para delimitar un modo de ver 


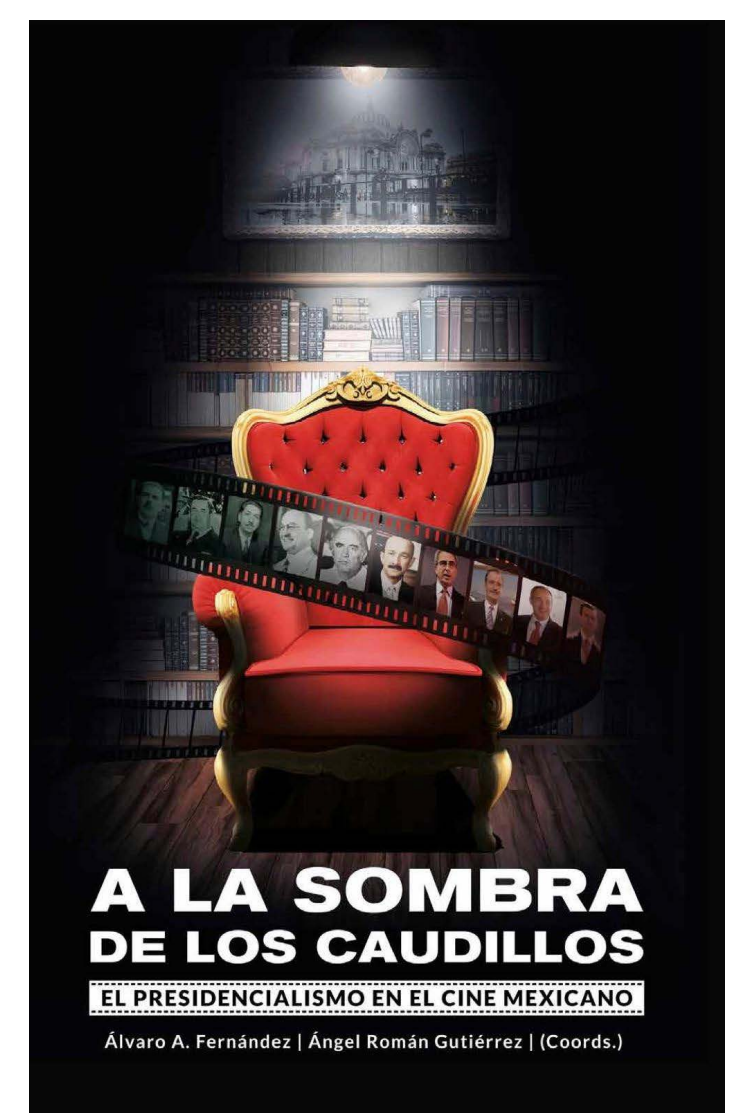

que tiene implicaciones en muchos de los ámbitos socioculturales de nuestro país, partiendo con la formación de públicos del cine nacional.

No puedo dejar pasar el atinado prólogo que escribe Marina Díaz. El texto aporta las claves para entender la naturaleza del presidencialismo mexicano. Con gran claridad, coloca las preguntas sobre gobernanza que pueden dimensionar el nivel de protagonismo de la figura presidencial en el devenir del cine y los medios audiovisuales nacionales.

Definitivamente el libro no tiene desperdicio. Sus tres primeros capítulos, escritos por David M. J. Wood, Carlos A. Belmonte Grey y Ángel Román Gutiérrez, se encargan de establecer las circunstancias contextuales bajo las que nace una industria cinematográfica al servicio del Estado. El encuadre ideológico revolucionario sentaría las bases del cine nacionalista y costumbrista que abriría el camino para el éxito de la comedia ranchera y del esplendor de la Época de Oro del cine mexicano.

Es durante el cardenismo (1934-1940), pasando después por el avilacamachismo (1940-1946) y cerrando con la debacle del cine mexicano en el periodo de Miguel Alemán (1946-1952), que las convenciones genéricas darían paso a la fijación de los signos de mexicanidad cargados de significados y valores patrióticos. Signos que esconden a plena vista las políticas de una representación y de una mirada simulada que, así como propone Baudrillard (1981), no es más que una ilusión de acercamiento a la realidad.

Francisco Peredo Castro pone particular énfasis en el fracaso de la política pública alemanista que, a pesar de sus esfuerzos por apropiarse de la industria del cine para sus fines propagandísticos, no consigue cumplir con el objetivo de fomentar una producción fílmica de alta calidad, ni tampoco pudo poner resistencia al monopolio de exhibición de William Jenkins. Es así como el sexenio de Miguel Alemán se distinguió por promulgar la primera Ley de la Industria Cinematográfica y sus brazos coercitivos que 
censuraron el cine que no era de interés nacional y privilegiaron la emergencia de un renovado cine nacional.

El libro continúa con un estupendo relato de Maximiliano Maza sobre el periodo presidencial de Adolfo López Mateos (1958-1964), en el que se le dio continuidad a la representación artificial del cine nacionalista mientras surgía un cine marginal crítico del estilo costumbrista romántico y de las figuras de autoridad representadas en la imagen del cacique. La censura aparece como el castigo impuesto por el Estado a las películas a que atentaran contra el orden simbólico y se manifestaría hasta alcanzar el sexenio de Gustavo Díaz Ordaz (1964-1970).

Yolanda Minerva Campos García se encarga de examinar el cambio en las políticas culturales durante el periodo del presidente Luis Echeverría (1970-1976). Con una política de apertura se impulsó una cultura cinematográfica que heredaba los logros del sexenio anterior, gestados al margen del Estado como una respuesta a la aguda crisis que amenazaba la producción nacional.

La urgencia de un cine nacional que estuviera en sintonía con los cambios culturales de la época, provocó un cambio generacional en los puestos creativos de la industria y por el surgimiento de espacios para la formación de cineastas y por el apuntalamiento que hace el gobierno a todo el proceso de producción cinematográfica. Una era de gloria y apertura, que se ve frustrada por el regreso de los productores y exhibidores de la industria privada durante el sexenio de José López Portillo (1976-1982). Campos argumenta que el sexenio de Luis Echeverría sentaría "las bases de la cultura cinematográfica contemporánea” (p. 165).

Antes de continuar hago un paréntesis para destacar la contribución de los docentes de cine a la construcción de un nuevo cine mexicano. Personajes que desde su experiencia profesional aplanaron el terreno para el surgimiento de la formación cinematográfica en nuestro país. Celebro el reconocimiento que hace 
la autora a la importancia de los profesores para el desarrollo de nuestro cine. Cierro el paréntesis.

Alejandro Pelayo se acerca a las causas de la cancelación de las políticas públicas impulsadas por el presidente Luis Echeverría. La reconciliación con el sector privado incentivó la producción fílmica de empresas como el grupo Televisa, mientras que desde el Estado se fomentaba la creación de un cine de entretenimiento de baja calidad cuyo propósito era generar ganancias inmediatas a sus productores.

El libro se acerca a su fin con una revisión de las lógicas neoliberales que derivaron en el desmantelamiento del subsidio público y en el surgimiento de otros públicos más cercanos al múltiplex de los centros comerciales que a los ahora lejanos cines de barrio. El texto de Ignacio M. Sánchez Prado toma como punto de partida la película Amores perros (Alejandro González Iñárritu, 2000) para revisar las implicaciones de las dinámicas del libre mercado en la producción cinematográfica y en la construcción de audiencias, que si bien perdió terreno en el campo de la exhibición, ganó libertades estéticas que lo llevaron a la producción de películas de gran calidad.

Cierro esta reseña con las valiosas reflexiones que realizan Mauricio Díaz Calderón, Alicia Vargas Amésquita, Diego Zavala Scherer, Alfredo González Reynoso y Álvaro A. Fernández. Cada uno de estos textos contribuye a la dialéctica entre cine y presidencialismo, objeto de este libro; sin embargo, sus referentes y singularidad brindan elementos significativos que agregan otras claves a la conversación.

El primero, escrito a cuatro manos por Mauricio Díaz Calderón y Alicia Vargas Amésquita, es un seductor relato que desmonta las secuencias de la película Río Escondido (Emilio Fernández, 1948) para observar con precisión la arquitectura simbólica que brinda orden y sentido a las representaciones del soberano, como una divinidad que aglutina el poder del Estado, y de la maestra 
Rosaura, servidora del Estado que representa la omnipresencia del régimen presidencial. El segundo texto, de Diego Zavala Scherer, piensa la representación del presidente desde el documental, analizando dos piezas del canal 16 de Julio. Zavala identifica los mecanismos de representación de la figura del presidente cuestionando su función dentro de la narrativa, pero también con el mundo al que interpela.

Alfredo González Reynoso analiza el filme Colosio: el asesinato (Carlos Bolado, 2012) y encuentra un discurso paradójico que cuestiona en su contenido al sistema político, pero que en su forma sugiere una simpatía por el sistema corrupto. Por último, Álvaro A. Fernández desenreda la compleja narrativa transmedia detrás del caso del Chapo Guzmán y la actriz Kate del Castillo. Al identificar las bifurcaciones de una historia expandida por múltiples medios, Fernández descubre los puentes entre el espectáculo y la política, una convergencia cultural que se transformó en un fenómeno comunicativo durante el periodo presidencial de Enrique Peña Nieto (2012-2018).

El o la lectora no se sentirá defraudada con este libro. En él, encontrará una revisitación a la historia de nuestro cine que es tan interesante como sugerente. Al final del libro, no se puede evitar pensar en el capítulo que se construye día a día con las políticas de desmantelamiento de la estructura cultural y artística del gobierno del presidente Andrés Manuel López Obrador.

Si es a la sombra de los caudillos que se ocultan los signos, las representaciones, la representatividad y la política que delimitó el frame cinematográfico del siglo XX y de la primera parte del siglo XXI, es en la penumbra que la comunidad cinematográfica de nuestro país puede encontrar la luz. 


\section{Bibliografía}

Baudrillard, J. (1981). Cultura y simulacro. Barcelona, España: Kairós.

Fernández, A. A. y Gutiérrez, A. M. (Coords.). (2020). A la sombra de los caudillos. El presidencialismo en el cine mexicano. Zacatecas, México: Universidad Autónoma de Zacatecas.

Vicente Addego Fernández (México) es profesor y productor audiovisual. Es Maestro en Comunicación de la Ciencia y la Cultura por el ITESO, en donde coordina la licenciatura en Comunicación y Artes Audiovisuales. Ha sido productor de programas de radio en el IMER y coordinador del Goya Cineclub de la unam. En el año 2018 fue becario del Fondo Nacional para la Cultura y las Artes con el proyecto sonoro de comunicación de la ciencia La batalla de las ciencias. 